\title{
MOTIVOS PARA MIGRAÇÃO NO BRASIL E RETORNO AO NORDESTE padrões etários, por sexo e origem/destino
}

\author{
Kleber Fernandes de Oliveira \\ Paulo de Martino Jannuzzi
}

\begin{abstract}
Resumo: Motivos de migração têm sido um tema poucas vezes levantado em pesquisas amostrais no país: estes só foram coletados recentemente na Pesquisa Nacional por Amostra de Domicílios - PNAD 2001. Este trabalho apresenta evidências empíricas desses motivos, analisando-os a partir do perfil etário e sexo do migrante e dos diferentes tipos de deslocamentos migratórios segundo origem e destino, destacando-se, em particular, o motivo de retorno para o Nordeste declarado pelos migrantes.

Palavras-chave: Migração. Motivos de migração. Padrão migratório.
\end{abstract}

\begin{abstract}
Reasons to migrate have not been frequently addressed in surveys in Brazil until 2001 National Household Survey. This paper brings empirical evidences on these type of information, analyzing on sex and age perspective and also on different types of migratory displacements framework. The reasons declared for migrants that return to the Northeast are also analyzed.

Key words: Migration. Reasons to migrate. Migratory patterns.
\end{abstract}

$\mathrm{P}$ oucas vezes os motivos de migração têm sido abordados em pesquisas amostrais no país. Embora presente em estudos de natureza qualitativa, as razões pessoais de migração foram apresentadas em raras oportunidades em surveys mais abrangentes como os reportados em Patarra et al. (1997). Há duas possíveis causas para esse fato. De um lado, há a dominância de modelos, abordagens e teorias interpretativas do fenômeno migratório como resultado dos desequilíbrios regionais dos fatores de produção (em especial, do trabalho). De outro, há a regularidade empírica do padrão etário dos migrantes (jovens, sobretudo homens de 15 a 29 anos de idade). Assim, surgiu a tendência de corroborar as teses aportadas por tais modelos e abordagens. O enfoque neoclássico sugere que os indivíduos migrariam em busca de trabalho, melhores oportunidades e salários, realizando um cálculo racional-econômico para a escolha do destino. Já a abordagem histórico-estruturalista indica que a formação dos fluxos de migrantes decorreria das necessidades e ditames do desenvolvimento econômico capitalista no país. Qualquer que seja o ponto de vista, os motivos da migração empreendi$\mathrm{da}$ - pessoal ou compulsoriamente - seriam os relacionados ao trabalho; e os protagonistas do processo, jovens em pleno potencial produtivo. Evidências apresentadas primeiramente por Ântico (1997) e aprofundadas em Jannuzzi $(1998 ; 2000)$ corroboram tais assertivas para o conjunto de migrantes no Estado de São Paulo no começo dos anos 90 .

Para o conjunto do país, só mais recentemente (na PNAD 2001) foram coletadas algumas informações sobre os motivos de migração. Foi nessa edição da pesquisa que incluía crianças, adultos e idosos - que foi levantado o motivo predominante para a realização do último movimento migratório nos últimos quatro anos, como um que- 
Motivos para Migração no Brasil e Retorno ao Nordeste:...

sito pré-codificado. Este trabalho procura trazer evidências empíricas desses motivos, analisando-os a partir do perfil etário e sexo do migrante e dos diferentes tipos de deslocamentos migratórios segundo origem e destino.

Para tanto, o texto está estruturado em três grandes tópicos. Inicia-se com uma apresentação dos resultados gerais da pesquisa sobre os motivos declarados, discriminado-os segundo idade e sexo dos migrantes. Em seguida, apresenta-se uma análise das motivações para migração, tendo como referência a região de origem e os destinos do processo. Por fim, devido à importância dos fluxos migratórios originados do Nordeste brasileiro, serão investigados os motivos envolvidos na migração de retorno à região, segundo diferentes perspectivas de análise.

\section{MOTIVOS DE MIGRAÇÃO SEGUNDO SEXO E FAIXA ETÁRIA DOS MIGRANTES}

Os modelos explicativos e esquemas interpretativos do fenômeno migratório - sejam eles formatados a partir de abordagem macro ou microssocial, inspirados em escola de orientação clássica ou histórico-estrutural - atribuem aos desequilíbrios espaciais de natureza econômica a determinação básica dos fluxos migratórios (SALIM, 1992; EBANKS, 1993). As desigualdades das taxas de crescimento econômico, da oferta de empregos e de nível de salários tenderiam a criar áreas propensas à evasão populacional e áreas destinadas à atração migratória, originando fluxos de pessoas em busca de trabalho ou melhores rendimentos. A disponibilidade de serviços públicos e políticas sociais nas áreas mais dinâmicas também constituiriam fatores potencializadores do fenômeno (BAENINGER, 1999).

A partir dessa perspectiva, os itens "busca por trabalho" e "acesso a serviços sociais" deveriam figurar entre as principais motivações declaradas para a migração. Não é o que aponta o levantamento de motivos de migração da PNAD 2001 no Brasil, o que poderia ser encarado, à primeira vista, como uma evidência a contraditar premissas tão caras à pesquisa na área. De fato, como mostra a Tabela 1, o motivo "acompanhar a família" é o mais mencionado na pesquisa, por mais da metade dos migrantes entrevistados, seguido de motivos relacionados ao trabalho, apontado por pouco menos de um quarto dos entrevistados como a principal razão do último deslocamento no país. Motivos relacionados ao custo da moradia figuram como o terceiro item mais importante para migração, sendo mencionado por $10 \%$ dos migrantes. Migrações motivadas por estudo ou por questões de saúde são muito menos fre-
TABELA 1

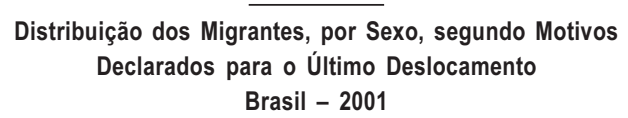

\begin{tabular}{lccc} 
& & \multicolumn{2}{c}{ Em porcentagem } \\
\hline Motivos Declarados & Homens & Mulheres & Total \\
\hline Total & 100,0 & 100,0 & 100,0 \\
Trabalho da Pessoa & 34,7 & 11,8 & 23,1 \\
Estudo da Pessoa & 2,7 & 3,2 & 2,9 \\
Saúde da Pessoa & 1,6 & 1,6 & 1,6 \\
Moradia & 11,0 & 9,4 & 10,2 \\
Acompanhar a Família & 39,6 & 63,0 & 51,5 \\
Dificuldade no Relacionamento & & & \\
Familiar & 1,5 & 2,4 & 2,0 \\
Outro Motivo & 8,9 & 8,5 & 8,7 \\
Ignorado & 0,1 & 0,1 & 0,1 \\
\hline
\end{tabular}

Fonte: IBGE. Pesquisa Nacional por Amostra de Domicílios - PNAD 2001.

qüentes no país $(2,9 \%$ e 1,6\% dos respondentes, respectivamente).

A importância de fatores microssociais como a necessidade de acompanhar a família já havia sido identificada anteriormente por Ântico (1997) a partir dos dados da pesquisa de campo do projeto "Migrações, emprego e projeções populacionais" (PATARRA et al., 1997). Por meio de entrevistas com os chefes de famílias migrantes residentes em 1993 no Estado de São Paulo, identificou-se que trabalho e motivos relacionados à família constituíam-se as justificativas mais citadas para a mudança para o município em que residiam por ocasião da pesquisa.

A não-primazia do trabalho como motivação principal para migração, na PNAD, deve-se, em primeiro lugar, ao fato de que o quesito acerca dos motivos de migração foi aplicado a todos os indivíduos que fizeram um deslocamento nos últimos quatro anos, indistintamente da idade. Assim, é natural que, para cada chefe de família que declarasse migrar em busca de trabalho, houvesse cônjuge e filhos que declarassem que o deslocamento decorria - para eles - como a necessidade de acompanhar o chefe ou os pais. De fato, dados da própria Tabela 1 corroboram essa assertiva, ao mostrar que, entre as mulheres, $63 \%$ declararam migrar pela necessidade de acompanhar a família, enquanto entre os homens, a cifra correspondente é significativamente mais baixa $(39,6 \%)$. Mas, mesmo entre os homens, os deslocamentos motivados por trabalho situam-se abaixo 
daqueles justificados pela necessidade de acompanhamento de familiares $(34,7 \%$ deles declararam ter migrado por trabalho, contra $39,6 \%$ por necessidade de acompanhar a família).

$\mathrm{O}$ fato de o trabalho não figurar como motivação principal da migração deve-se também, como já observado, à presença de filhos na amostra de entrevistados. Como mostra a Tabela 2, a necessidade de acompanhar a família é o motivo predominante (mais de $80 \%$ ) entre crianças e adolescentes até 14 anos. Já para migrantes pertencentes à força de trabalho primária, com 25 até 49 anos de idade, o trabalho é claramente o motivo mais importante, corroborando extensa bibliografia de natureza empírica (JANNUZZI, 1998). De modo geral, jovens em seus 20 e poucos anos estariam sujeitos a migrar mais do que qualquer outro grupo etário. Esse padrão etário de mobilidade estaria condicionado, sobretudo, aos ciclos de entrada e saída do mercado de trabalho. Assim, a elevada concentração de jovens entre os migrantes seria explicada pela maior sensibilidade dos mesmos com relação às ofertas de trabalho e de melhores empregos, assim como pela maior adaptabilidade a novas situações e maior desprendimento em deixar seu ambiente de origem.
A necessidade de acompanhar o cônjuge em casais recém-formados, assim como a busca de oportunidades de formação educacional e profissional em centros regionais maiores também seriam outros fatores mobilizadores de jovens, sobretudo aqueles na faixa de 15 a 24 anos. Há mais de um século, em suas "Leis da Migração", Ravenstein já havia identificado tal característica do fenômeno migratório, ao apontar a predominância da migração de moças pelo casamento e de rapazes em busca de trabalho.

De fato, entre os jovens nessa faixa, além do trabalho e da necessidade de acompanhar a família, a migração motivada por estudo também se mostra relativamente importante. Entre os migrantes mais idosos, a migração forçada por contingências familiares passa a ter papel mais importante que o trabalho. Migração motivada por questões de saúde e moradia (morar com parentes, morar no interior, etc.) também passam a ser mais importantes.

Como já foi observado, a migração motivada por questões relacionadas à moradia é bem menos freqüente que as motivadas por trabalho e pela necessidade de acompanhar a família. Contudo, tal tipo de migração passa a ser mais significativa a partir das idades próximas à formação do núcleo familiar, a partir dos 20 a 24 anos, crescendo de

TABELA

Distribuição dos Migrantes, por Motivos Declarados para o Último Deslocamento, segundo Faixa Etária

Brasil - 2001

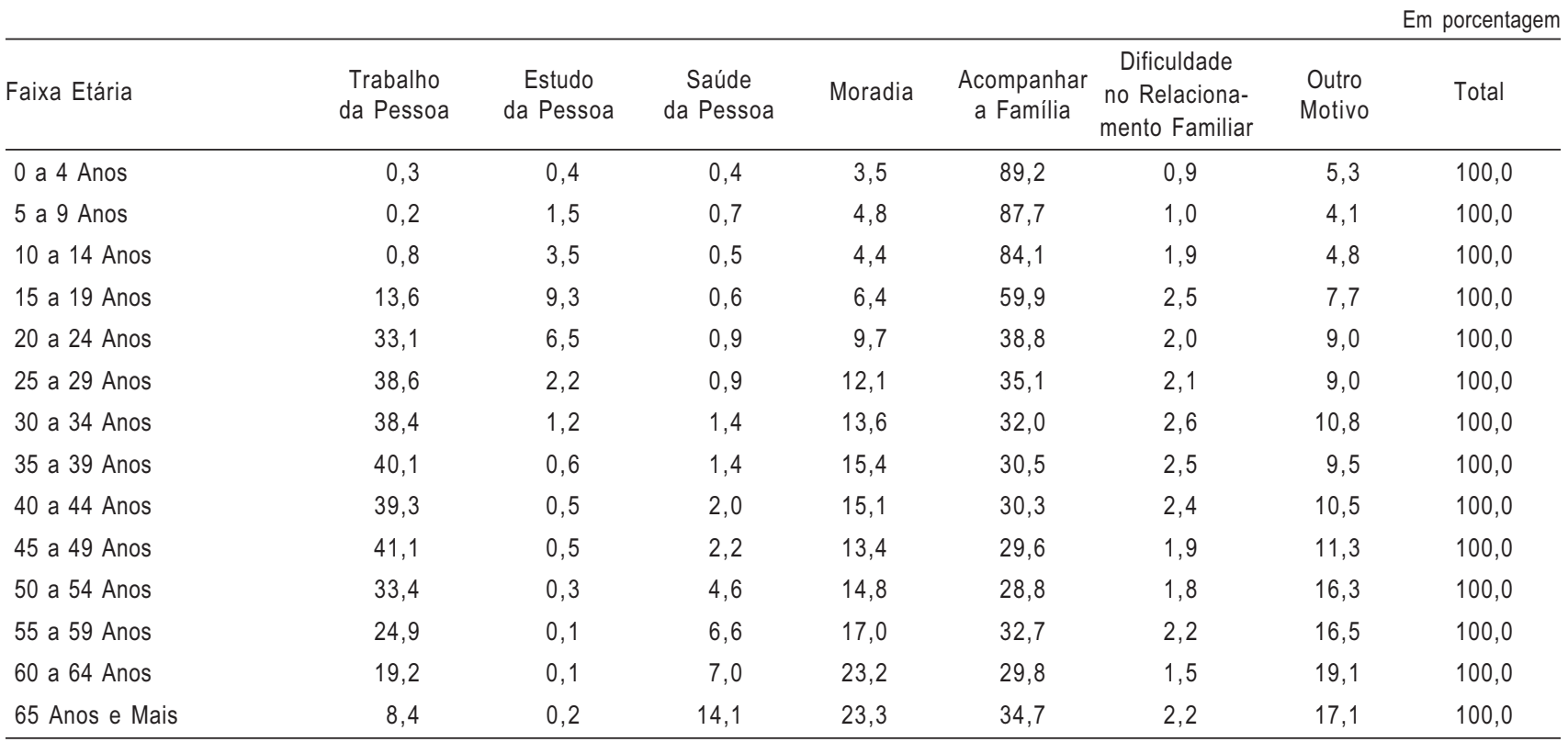

Fonte: IBGE. Pesquisa Nacional por Amostra de Domicílios - PNAD 2001. 


\section{GRÁFICO 1}

Taxas Migratórias, por Sexo e Faixa Etária, segundo Motivos Declarados para Último Deslocamento Brasil - 2001
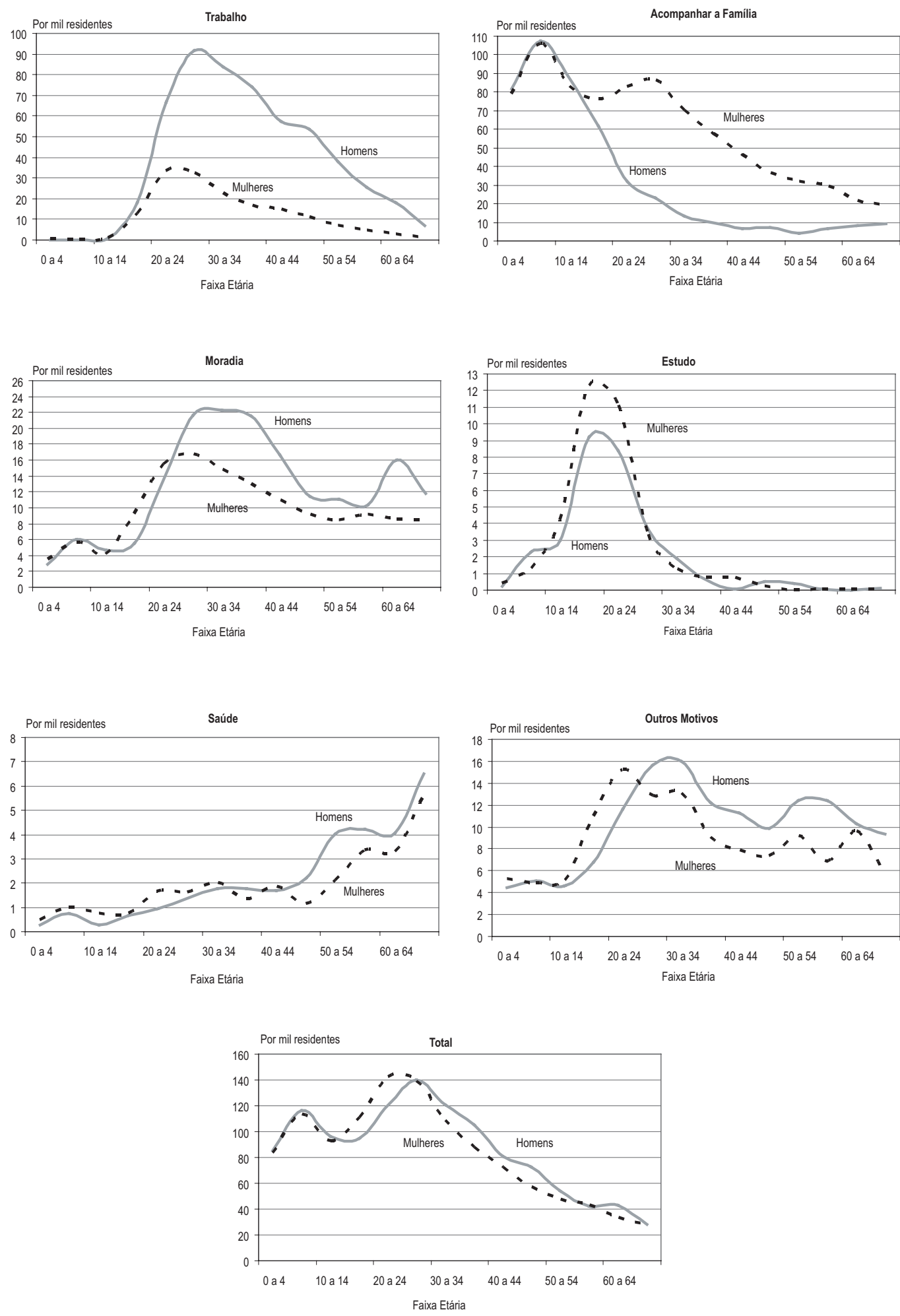

Fonte: IBGE. Pesquisa Nacional por Amostra de Domicilios - PNAD 2001 
importância até as idades mais avançadas. Entre os jovens de 20 a 24 anos, 9,7\% declararam ter migrado por necessidade de uma nova moradia. No estágio mais avançado do ciclo vital e familiar, entre os migrantes de 65 anos ou mais, essa cifra passa a $23 \%$, desbancando, inclusive o trabalho como segundo motivo mais citado. A necessidade de uma moradia para abrigar uma nova família (Quem casa quer casa!), a busca de locais mais seguros e dotados de infraestrutura de serviços para criação dos filhos, a procura de cidades e bairros mais aprazíveis ou de custos mais baixos de vida na aposentadoria explicam o comportamento desse tipo de migração ao longo do ciclo de vida.

Essas mesmas características podem ser ilustradas por meio das curvas delineadas pelas taxas específicas de migração por motivos, calculadas como quocientes de migrantes por mil pessoas (migrantes ou não) nas faixas qüinqüenais de idade, para cada sexo, reproduzindo - no que é possível comparar - as curvas descritas em Jannuzzi (1998). Assim, observa-se com clareza o padrão fortemente modal e concentrado da migração por trabalho nas faixas de 20 a 39 anos, e sua incidência acentuada entre homens. A migração associada à necessidade de acompanhar a família apresenta um padrão com taxas elevadas nas primeiras idades, para ambos os sexos, com pico na faixa de 5 a 9 anos, com magnitudes próximas ao alcançado pelos homens nas principais faixas de idade produtiva que migram por trabalho. Entre as mulheres, a curva é bimodal, com outro pico nas idades próximas ao casamento (20 a 29 anos), decrescendo gradativamente a partir de então. Refletindo os processos associados à formação e expansão do núcleo familiar, as taxas de migração motivada por questões relacionadas à moradia (busca por moradia mais barata, em local mais seguro, etc.) atingem níveis mais elevados na faixa de 25 a 34 anos para homens, e um pouco mais cedo no caso das mulheres (em função da idade ao casar, um pouco menor para as últimas). Como era de se esperar, as taxas de migração por estudo têm formato sinoidal, atingindo valores mais elevados dos 15 aos 24 anos. $O$ fato de as taxas serem um pouco mais elevadas para as mulheres talvez se deva a que homens nessas faixas etárias estejam mais propensos a se engajar no mercado de trabalho. A migração por motivos de saúde exibe um padrão crescente com o aumento da idade, apontando a necessidade de pessoas mais velhas retornarem às cidades de origem, ou se deslocarem em busca de tratamento, de parentes ou até mesmo de asilos em outras localidades. A migração residual (por outros motivos) revela um padrão etário também sinoidal, com cúspide mais tardia que a da migração por trabalho.

\section{MOTIVOS DE MIGRAÇÃO SEGUNDO ORIGEM E DESTINO DOS MIGRANTES}

A análise da motivação para mudança de município segundo local de residência dos migrantes por ocasião da pesquisa revela algumas especificidades do processo pelas regiões do país, embora em todas elas a migração motivada pela necessidade de acompanhamento da família atinja mais de $40 \%$ das declarações, sendo que a migração por trabalho, em geral, figura em segundo lugar.

No Norte, a migração por estudo é comparativamente mais citada pelos indivíduos, possivelmente pelas grandes distâncias em que se localizam as escolas de ensino médio e faculdades na região; para migrantes residentes no Nordeste, a mudança motivada por busca de trabalho, por outro lado, não tem a incidência relativa identificada em outras regiões, especialmente se comparada com áreas de economia mais dinâmica, como a Região Metropolitana de São Paulo - RMSP e interior paulista.

Para residentes nas duas principais regiões metropolitanas do país, a mudança induzida por busca de moradia em local mais aprazível ou de custo mais baixo é significativamente mais alta, como era de se esperar, seja pelos fluxos voluntários de saída da classe média dos grandes centros, seja pela expulsão involuntária da população de baixa renda dos distritos mais centrais das metrópoles em direção às periferias. Vale lembrar que essa motivação também envolve aquelas pessoas que buscam as áreas metropolitanas devido à maior concentração de equipamentos sociais - característica que reforça a hipótese de a moradia representar uma motivação de caráter mais funcional. Na direção inversa, nota-se a pouca expressividade dessa motivação no Norte brasileiro e no interior paulista.

Esses resultados podem ser analisados de forma ainda mais refinada a partir da identificação de alguns fluxos específicos de origem e destino, como os que partem do Nordeste para a Região Metropolitana de São Paulo ou para o Centro-Oeste (em especial Brasília) e aqueles de migrantes sulistas para Centro-Oeste e Norte do país (Tabela 4). Cerca de $36 \%$ dos migrantes que se dirigiram do Nordeste para a RMSP mencionaram o trabalho como principal fator; parcela muito próxima (37\%) declarou o mesmo motivo para escolha de municípios na Região Centro-Oeste do país. Esses resultados reafirmam a análise apresentada em Jannuzzi (2000) para explicar a robustez dos fluxos de migrantes nordestinos para São Paulo, mesmo em conjunturas econômicas desfavoráveis. 
Motivos para Migração no Brasil e Retorno ao Nordeste:...

TABELA 3

Distribuição dos Migrantes, por Região de Residência, segundo Motivos Declarados para o Último Deslocamento

Brasil - 2001

\begin{tabular}{|c|c|c|c|c|c|c|c|c|}
\hline & & & & & & & & m porcentagem \\
\hline Motivos Declarados & Norte & Nordeste & Sudeste & Sul & $\begin{array}{l}\text { Centro- } \\
\text { Oeste }\end{array}$ & RMRJ & RMSP & $\begin{array}{l}\text { Interior de } \\
\text { SP }\end{array}$ \\
\hline Total & 100,0 & 100,0 & 100,0 & 100,0 & 100,0 & 100,0 & 100,0 & 100,0 \\
\hline Trabalho da Pessoa & 22,9 & 18,4 & 24,2 & 26,0 & 26,2 & 21,8 & 26,6 & 25,6 \\
\hline Estudo da Pessoa & 5,0 & 3,1 & 2,3 & 2,8 & 3,5 & 1,6 & 3,2 & 1,6 \\
\hline Saúde da Pessoa & 1,2 & 2,0 & 1,4 & 1,7 & 1,4 & 1,2 & 1,0 & 1,0 \\
\hline Moradia & 6,8 & 11,1 & 11,3 & 9,2 & 7,3 & 18,0 & 14,6 & 6,4 \\
\hline Acompanhar a Família & 54,6 & 51,5 & 50,0 & 52,1 & 53,7 & 42,1 & 45,8 & 56,2 \\
\hline $\begin{array}{l}\text { Dificuldade no Relacionamento } \\
\text { Familiar }\end{array}$ & 2,4 & 2,3 & 1,8 & 1,7 & 1,8 & 3,1 & 1,8 & 1,1 \\
\hline Outro Motivo & 7,0 & 11,7 & 8,6 & 6,5 & 6,0 & 10,9 & 7,1 & 8,1 \\
\hline Ignorado & 0,1 & - & 0,3 & - & - & 1,5 & - & - \\
\hline
\end{tabular}

Fonte: IBGE. Pesquisa Nacional por Amostra de Domicílios - PNAD 2001.

TABELA 4

Distribuição dos Migrantes, por Direção dos Fluxos, segundo Motivos Declarados para o Último Deslocamento

Brasil - 2001

\begin{tabular}{|c|c|c|c|c|c|c|}
\hline Motivos Declarados & $\begin{array}{l}\text { NE para } \\
\text { RMSP }\end{array}$ & $\begin{array}{c}\text { ESP } \\
\text { para NE }\end{array}$ & $\begin{array}{c}\text { NE para } \\
\text { Centro-Oeste }\end{array}$ & $\begin{array}{c}\text { Centro-Oeste } \\
\text { para NE }\end{array}$ & $\begin{array}{c}\text { Sul para } \\
\text { Norte + } \\
\text { Centro-Oeste }\end{array}$ & $\begin{array}{c}\text { Norte }+ \\
\text { Centro-Oeste } \\
\text { para Sul }\end{array}$ \\
\hline Total & 100,0 & 100,0 & 100,0 & 100,0 & 100,0 & 100,0 \\
\hline Trabalho da Pessoa & 36,4 & 19,1 & 37,0 & 14,0 & 36,1 & 29,5 \\
\hline Estudo da Pessoa & 1,7 & 1,2 & 5,0 & 2,1 & 1,8 & 3,2 \\
\hline Saúde da Pessoa & 0,6 & 2,7 & 1,6 & 2,7 & 0,3 & 2,1 \\
\hline Moradia & 12,6 & 12,1 & 6,1 & 8,1 & 2,2 & 6,6 \\
\hline Acompanhar a Família & 44,4 & 42,6 & 42,7 & 48,6 & 53,8 & 51,2 \\
\hline Dificuldade no Relacionamento Familiar & 1,0 & 2,8 & 2,2 & 2,7 & 1,0 & 1,8 \\
\hline Outro Motivo & 3,4 & 19,4 & 5,5 & 21,8 & 4,8 & 5,5 \\
\hline Ignorado & - & - & - & - & - & - \\
\hline
\end{tabular}

Fonte: IBGE. Pesquisa Nacional por Amostra de Domicílios - PNAD 2001.

Entre os sulistas, $36,1 \%$ daqueles que se dirigiram para a Fronteira Centro-Oeste/Norte o fizeram em busca de trabalho. A comparativamente alta incidência de declaração de outros motivos por migrantes partindo de São Paulo ou Centro-Oeste em direção ao Nordeste é reveladora de que parte da migração de retorno é motivada por fatores possivelmente relacionados ao insucesso de inserção laboral ou de adaptação.
Os fluxos migratórios partindo de Minas Gerais, seja para São Paulo, seja para Centro-Oeste, têm forte motivação laboral, como mostra a Tabela 5. Também compartilha dessa característica a mobilidade de pessoas dentro do Estado de São Paulo e, curiosamente, - mesmo com as dificuldades do mercado de trabalho carioca -, a migração que se origina nos municípios no interior do Rio de Janeiro e se desloca para a Região Metropolitana do Rio de Ja- 
TABELA 5

Distribuição dos Migrantes Internos, por Direção dos Fluxos, segundo Motivos Declarados para o Último Deslocamento São Paulo e Rio de Janeiro - 2001

Em porcentagem

\begin{tabular}{|c|c|c|c|c|c|c|c|}
\hline Motivos Declarados & $\begin{array}{c}\text { Intra- } \\
\text { estadual com } \\
\text { Residência } \\
\text { na RMSP }\end{array}$ & $\begin{array}{c}\text { Intra- } \\
\text { estadual com } \\
\text { Residência } \\
\text { no Interior } \\
\text { de SP }\end{array}$ & $\begin{array}{l}\text { Intra- } \\
\text { estadual com } \\
\text { Residência } \\
\text { na RMRJ }\end{array}$ & $\begin{array}{l}\text { Intra- } \\
\text { estadual com } \\
\text { Residência } \\
\text { no Interior } \\
\text { do RJ }\end{array}$ & $\begin{array}{c}\text { MG para } \\
\text { SP }\end{array}$ & $\begin{array}{c}\text { MG para } \\
\text { Centro-Oeste }\end{array}$ & Total \\
\hline Total & 100,0 & 100,0 & 100,0 & 100,0 & 100,0 & 100,0 & 100,0 \\
\hline Trabalho da Pessoa & 38,8 & 32,8 & 31,2 & 21,7 & 30,9 & 33,6 & 33,8 \\
\hline Estudo da Pessoa & 3,6 & 1,2 & 1,9 & 3,0 & 2,3 & 3,5 & 2,5 \\
\hline Saúde da Pessoa & 1,0 & 1,4 & 0,3 & 0,5 & 2,3 & 3,2 & 1,4 \\
\hline Moradia & 7,5 & 3,0 & 6,1 & 3,9 & 8,0 & 7,7 & 6,0 \\
\hline Acompanhar a Família & 41,0 & 53,8 & 41,4 & 63,1 & 44,1 & 45,8 & 46,4 \\
\hline Dificuldade no Relacionamento Familiar & 1,4 & 0,4 & 1,0 & 3,9 & 2,0 & 1,8 & 1,3 \\
\hline Outro Motivo & 6,7 & 7,4 & 14,6 & 3,9 & 10,5 & 4,4 & 8,1 \\
\hline Ignorado & - & - & 3,5 & - & - & - & 0,4 \\
\hline
\end{tabular}

Fonte: IBGE. Pesquisa Nacional por Amostra de Domicilios - PNAD 2001.

neiro - RMRJ. Como já foi observado anteriormente, as questões relacionadas à moradia explicam parte significativa da migração intrametropolitana na RMSP e RMRJ, a julgar pelas aproximações a que se pode chegar quanto a seu dimensionamento (não passível de mensuração precisa na PNAD).

\section{MOTIVOS DE MIGRAÇÃO DE RETORNO: O CASO DO NORDESTE}

O Nordeste brasileiro tem-se caracterizado como uma área de intensos fluxos emigratórios. No cerne desses movimentos podem ser localizados alguns fatores historicamente conhecidos, como a estagnação econômica, as mais diversas manifestações de desigualdades sociais, sobretudo os elevados níveis de desemprego nas áreas urbanas da região.

As transformações na estrutura produtiva brasileira e as novas configurações do desenvolvimento regional que se delineiam a partir da década de 70 ambientam importantes modificações na dinâmica migratória nordestina. O processo de desconcentração econômica, amparado pelas políticas de incentivo ao investimento industrial no Nordeste, influencia o comportamento da migração nordestina na década de 80 , onde se destacam os fluxos de retorno (CUNHA; BAENINGER, 2000). Na década de 90, a migração originada do Nordeste reaquece o comportamento do período que se estende até os anos 70, no qual se destacam os fluxos para o Sudeste e Centro-Oeste, sendo que essa retomada ocorre ao mesmo tempo em que a migração de retorno à região também intensifica os seus fluxos, constituindo, assim, uma novidade revelada pelo Censo Demográfico 2000 (OLIVEIRA, 2003).

Nesse contexto, cumpre mencionar os reflexos das políticas públicas de planejamento urbano e regional, encetadas na região a partir da década de 70 , que visavam a estruturar as cidades médias de forma que elas atuassem na redução das disparidades regionais através da interiorização do desenvolvimento e que absorvessem parte dos fluxos migratórios que se destinam às metrópoles (AMORIM FILHO; SERRA, 2001). A estruturação desses centros contou com um célere processo de expansão de conjuntos habitacionais, cujas unidades financiadas pelo governo certamente acabaram atraindo migrantes internos e os de retorno. O caráter seletivo dos investimentos nos setores não-tradicionais (química, metalurgia, minerais nãometálicos, papel e celulose) impôs à região uma feição diferente daquela caracteristicamente produtora de bens de consumo não-duráveis (cana-de-açúcar, algodão). Tal seletividade também teve rebatimentos no espaço nordestino devido à tendência de o movimento de industrialização convergir para as áreas que apresassem certos atributos (tamanho populacional, capacidade de articulação com outros centros de hierarquias distintas, etc.). Ao longo dessas décadas, tais modificações fazem surgir novas con- 
figurações regionais, de que são exemplo os espaços produtivos modernos como o complexo petroquímico de Camaçari (BA), o pólo têxtil e de confecções de Fortaleza (CE), o complexo mínero-metalúrgico de Carajás (MA), o pólo agroindustrial de Petrolina (PE)/Juazeiro (BA), a fruticultura do Rio Grande do Norte e a pecuária intensiva no Agreste pernambucano (ARAÚJO, 2000a).

Essas transformações na estrutura econômica nordestina constituem o ambiente sobre o qual pode-se, agora, analisar a participação do trabalho e outros fatores no conjunto de motivações para retornar à região. Antes, porém, são necessários alguns esclarecimentos metodológicos acerca da definição da migração de retorno, já que ela pode ser estudada a partir de duas modalidades. A primeira, denominada de retorno de única etapa refere-se à pessoa que, retornada à unidade federativa - UF de naturalidade, possui igual tempo de residência no município de enumeração, podendo ser enumerada no município que nasceu ou não. O retorno com mais de uma etapa, por sua vez, é realizado pela pessoa que, após ter retornado à UF de naturalidade, efetua etapas migratórias dentro do estado, antes de, finalmente, ser enumerado no município de nascimento ou outro qualquer - o que justifica ser o tempo de residência no município de enumeração inferior ao verificado na UF (RIBEIRO, 1997).

Tal distinção metodológica impõe também diferenças quantitativas, ou seja, ao se considerar como migrante de retorno aquela pessoa que retorna à UF de naturalidade, mas que realiza movimentos migratórios intermunicipais, obtém-se possivelmente uma população retornada mais numerosa. Entretanto, a pertinência de considerar-se esse movimento pode ser questionada através do argumento de que, ao realizar a migração entre municípios, esse migrante deixa de ser "de retorno" e passa a ser "interno". Este artigo compartilha dessa idéia e define como migrante de retorno aquela pessoa natural do município e que possuía até quatro anos de residência ininterrupta no lugar (retorno ao município de nascimento), ou o natural da UF com até quatro anos de residência no município atual em que foi entrevistado (retorno à UF de naturalidade, mas a outro município que não o de nascimento).

Valendo-se das observações da Tabela 6 referentes à participação relativa de cada motivo, segundo fluxos de retorno, observa-se que acompanhar a família é o principal motivo da migração, como já foi assinalado para todos os demais fluxos aqui estudados, em função das características do levantamento (realizado junto a todas as pessoas da família migrante). Considerando as áreas originárias dos fluxos de retorno, o peso desse motivo apresenta-se maior na região Norte, sendo apontado por $51,1 \%$ dos mais de 119 mil retornados a essa região. Nas regiões Nordeste e Centro-Oeste, esse motivo foi apontado por cerca de $44 \%$ dos retornados, enquanto que, dos originados do Estado de São Paulo, 35,7\% apontaram esse motivo.

TABELA 6

Distribuição dos Migrantes, por Principais Origens dos Fluxos de Retorno para o Nordeste, segundo Motivos Declarados para o Último Deslocamento Brasil - 2001

\begin{tabular}{|c|c|c|c|c|c|c|c|c|}
\hline \multirow[b]{2}{*}{ Motivos Declarados } & \multicolumn{6}{|c|}{ Origem do Retorno } & \multicolumn{2}{|c|}{ Total } \\
\hline & Norte & Nordeste & $\begin{array}{c}\text { Sudeste } \\
\text { (Exceto SP) }\end{array}$ & SP & Sul & $\begin{array}{l}\text { Centro- } \\
\text { Oeste }\end{array}$ & $\%$ & $\begin{array}{c}\text { Nos } \\
\text { Absolutos }\end{array}$ \\
\hline Total (Nos Absolutos) & 119.919 & 255.001 & 169.642 & 537.502 & 12.187 & 139.357 & & 1.233 .608 \\
\hline Total (\%) & 100,0 & 100,0 & 100,0 & 100,0 & 100,0 & 100,0 & 100,0 & \\
\hline Trabalho da Pessoa & 21,3 & 20,0 & 18,3 & 22,2 & 24,9 & 13,2 & 20,1 & 248.128 \\
\hline Estudo da Pessoa & 3,0 & 3,5 & 1,4 & 1,1 & 0,0 & 2,4 & 2,0 & 24.086 \\
\hline Saúde da Pessoa & 4,7 & 1,3 & 3,8 & 3,2 & 0,0 & 3,6 & 3,1 & 37.698 \\
\hline Moradia & 9,0 & 10,1 & 12,0 & 12,5 & 13,7 & 8,9 & 11,2 & 137.779 \\
\hline Acompanhar a Família & 51,1 & 44,8 & 39,1 & 35,7 & 37,2 & 44,1 & 40,5 & 499.699 \\
\hline $\begin{array}{l}\text { Dificuldade no Relacionamento } \\
\text { Familiar }\end{array}$ & 2,1 & 3,9 & 4,9 & 2,9 & 12,4 & 3,0 & 3,4 & 41.763 \\
\hline Outro Motivo & 8,8 & 16,5 & 20,6 & 22,5 & 11,8 & 24,8 & 19,8 & 244.455 \\
\hline
\end{tabular}

Fonte: IBGE. Pesquisa Nacional por Amostra de Domicilios - PNAD 2001. 
O item trabalho figura como a segunda motivação de retorno, sendo declarado por $20,1 \%$ do total dos retornados, cifra essa que assume valores um pouco mais altos dentre os da Região Sul, São Paulo e Região Norte. Entre 1997 e 2001, cerca de 248 mil pessoas retornaram ao Nordeste motivadas principalmente pelo trabalho, sendo que, desse total, 150,2 mil pessoas provenientes da região Sudeste. De um lado, as crises econômicas que marcaram toda a década de 90 aumentaram as dificuldades de inserção, ou mesmo de manutenção laboral, nos grandes centros urbanos - e, assim, favoreceram a intensificação do retorno ao Nordeste. Nessa região, por sua vez, os reflexos das transformações econômicas regionais, como as acima aludidas, contribuíram ainda mais no direcionamento desses fluxos, embora o dinamismo econômico nordestino já apresentasse sinais de estagnação. Vale acrescentar também que a demanda por postos de trabalho no mercado nordestino, que já se mostrava pressionado desde o início dos anos $90,{ }^{1}$ torna-se maior na medida em que cerca de 248 mil pessoas exercem de forma direta essa busca, da mesma forma que indiretamente as demais pessoas que migraram por outro motivo - como, por exemplo, os que acompanham a família.

A pequena importância do motivo estudo pode ser explicada, ademais da idade mais adiantada dos migrantes de retorno, pelo relativo atraso do sistema educacional nordestino, embora algumas universidades como as Federais de Pernambuco, Bahia e Ceará já despontem como centros de referência nas Ciências Exatas e Sociais Aplicadas.

Com maior expressividade, aparecem os motivos relacionados com a moradia. Note-se que, dos mais de 1,2 milhão de pessoas consideradas como migrantes de retorno ao Nordeste, pouco mais de $11 \%$ apontaram esse motivo. Dentre os fluxos regionais, merecem destaque provenientes do Sul, com $13,7 \%$, sobretudo aqueles retornados do Sudeste - exceto São Paulo, com 12\% e do Estado de São Paulo, com 12,5\%.

Mas o que realmente desponta como motivação diferenciada para a migração de retorno para o Nordeste é a importância dos outros motivos. Note-se que ela é citada com maior intensidade pelos migrantes que retornaram à região, em especial de áreas tradicionalmente receptoras de nordestinos, para lá deslocados por motivo de trabalho (além de acompanhamento da família). Assim, cerca de um quarto dos migrantes que retornaram do Centro-Oeste, declararam outros motivos para justificar o retorno; entre os que retornaram do Estado de São Paulo, a cifra equiva- lente é de 22,5\%. Como são essas as duas regiões onde a migração de nordestinos por trabalho é mais intensa, como já foi mostrado anteriormente (Tabela 4), é plausível conjecturar que, dentre as possíveis razões subentendidas nessa resposta (outros motivos), destaquem-se fatores como a dificuldade de inserção laboral no local de residência anterior, seja pela elevada competitividade do mercado formal, seja pela instabilidade do setor informal do mercado de trabalho. Além disso, o agravamento da violência nos grandes centros do Sudeste, manifestado no aumento das mortes por causas externas contra a pessoa - e, em especial, daquelas em idade economicamente ativa -, também deve ser outra razão subentendida dentro dessa categoria residual outros motivos.

\section{CONSIDERAÇÕES FINAIS}

Este trabalho procurou trazer elementos empíricos acerca das motivações declaradas pelos indivíduos para migração para o município de residência por ocasião da residência. A necessidade de acompanhar a família e a busca por trabalho revelaram-se as motivações mais importantes para a mudança para o município atual. A primeira, por mulheres; a segunda, por homens - especialmente os provenientes do Nordeste e aqueles que se dirigem, dentre as áreas estudadas, à RMSP ou ao interior de São Paulo. Mudanças motivadas por questões relativas ao custo da moradia tendem a ser mais freqüentes para pessoas residentes ou que saíram de regiões metropolitanas. Migração por motivos de saúde tende a ser um item mais importante para migrantes em ciclo vital mais avançado. Ainda que esses resultados pareçam fazer sentido e revelem-se bastante consistentes com achados anteriores, é oportuno lembrar que declarações sobre motivos de migração - como tantas outras questões opinativas em pesquisas amostrais estão sujeitas a erros de memória e racionalizações post facto, de modo a reduzir a dissonância entre a atitude do indivíduo e sua intenção à época de migração.

Se é fato que não se pode sobrevalorizar fatores microssociais em detrimento das causas macroestruturais no entendimento dos processos sociais, os resultados aqui apresentados ilustram, no campo de estudos migratórios, a contribuição analítica complementar que a primeira ordem de fatores - motivações individuais - pode trazer à interpretação das nuances que o fenômeno manifesta estruturalmente. No caso dos fluxos de retorno ao Nordeste, existem outras variáveis macroestruturais, além das apontadas neste texto, que devem ser consideradas na in- 
terpretação do crescente interesse verificado nos migrantes com idade superior aos 55 anos, da mesma forma que a retomada dos fluxos destinados ao Sudeste não pode mais ser explicada pelos mesmos elementos utilizados nos anos 70 e 80.

\section{NOTA}

1. Devido à intensificação do crescimento populacional dos anos 70, resultante do balanço positivo entre as elevadas taxas de fecundidade e do intenso processo de redução da mortalidade.

\section{REFERÊNCIAS BIBLIOGRÁFICAS}

AMORIM FILHO, O.; SERRA, R.V. Evolução e perspectivas do papel das cidades médias no planejamento urbano e regional. In: ALMEIDA, T; SERRA, R. (Org.). Cidades médias brasileiras. Rio de Janeiro: Ipea, 2001.

ANDRADE, M.C. A terra e o homem no Nordeste. 2. ed. São Paulo: Brasiliense, 1964.

ÂNTICO, C. Por que migrar? In: PATARRA, N. et al. Migrações, condições de vida e dinâmica urbana. Campinas: Instituto de Economia Unicamp/Fapesp, 1997.

ARAÚJO, T.B. Industrialização do Nordeste: Intenções e resultados. In: Ensaios sobre o desenvolvimento brasileiro: heranças e urgências. Rio de Janeiro: Revan/Fase, 2000a. p. 143154.

Nordeste, Nordestes: Que Nordeste? In: Ensaios sobre o desenvolvimento brasileiro: heranças e urgências. Rio de Janeiro: Revan/Fase, 2000b. p. 165-196.

BAENINGER, R. Região, Metrópole e Interior: espaços ganhadores e espaços perdedores nas migrações recentes no Brasil, 1980/1996. Tese (Doutorado) - Instituto de Filosofia e Ciências Humanas/Unicamp, Campinas, 1999.

CUNHA. J.M.; BAENINGER, R. A migração nos estados brasileiros, no período recente: principais tendências e mudança. In: ENCONTRO NACIONAL SOBRE MIGRAÇÃO, 2., Anais... Belo Horizonte: Abep, 2000. p. 117-165.
EBANKS, G.E. Determinantes socioecónomicos de la migración interna. Santiago: Celade, 1993.

ELIZAGA, J. Dinámica y economía de la población. Santiago: Celade, 1979

JANNUZZI, P. de M. Migração e mobilidade social. Campinas, Ed. Autores Associados/Fapesp, 2000. 240 p.

Perfis etários da migração por motivos e acompanhantes da mudança: evidências empíricas para São Paulo entre 1980 e 1993. Revista Brasileira de Estudos da População, Brasília, DF, v. 15, n. 2, p. 19-44, 1998.

OLIVEIRA, K.F. Dinâmica migratória em Sergipe: uma abordagem a partir de alguns fatores estruturais. Dissertação (Mestrado) - Escola Nacional de Ciências Estatísticas/IBGE, Rio de Janeiro, 2003.

PATARRA, N. et al. Migrações, condições de vida e dinâmica urbana. Campinas: Instituto de Economia Unicamp/Fapesp, 1997.

RIBEIRO, J.T.L. Estimativa da migração de retorno e de alguns de seus efeitos demográficos indiretos no Nordeste Brasileiro, 1970/1980 e 1981/1991. Tese (Doutorado em Demografia) - Cedeplar/UFMG, Belo Horizonte, 1997.

SALIM, C. Migração: o fato e a controvérsia. In: ENCONTRO NACIONAL DE ESTUDOS POPULACIONAIS, 8., Anais.. Brasília: Abep, v. 3, p. 119-143, 1992.

Kleber Fernandes de Oliveira: Professor do Departamento de Economia da Universidade Mackenzie - SP. Mestre em Estudos Populacionais e Pesquisa Social (kleber@mackenzie.com.br).

Paulo de Martino Jannuzzi: Assessor da Diretoria Executiva da Fundação Seade - SP. Professor do Mestrado em Estudos Populacionais e Pesquisas Sociais da ENCE/IBGE - RJ.

Artigo recebido em 23 de fevereiro de 2005

Aprovado em 22 de março de 2005. 